\title{
A New Approach for Construction Engineering Design Management Research Based on BIM
}

\author{
LIU Qing ${ }^{1, a}$ \\ ${ }^{1}$ Qinghai University, Xining 810016, China \\ aliuqing@126.com
}

Keywords: Construction Engineering, Design Management, Building Information Modeling

\begin{abstract}
BIM in construction projects in our country and related software application level gradually improve, plus many architectural design units have through the adoption of BIM technology improve the quality of design results. For most enterprises, how to improve the efficiency of the BIM design become the key to BIM can be widely used. Due to the field of architectural design has formed a mature $2 \mathrm{~d}$ drawings of the design process, the new design method based on BIM technology is not very adapt. This article elaborates the design concept and the significance of based on BIM, on the basis of practice put forward a set of design methods and processes, the paper points out its application practice.
\end{abstract}

\section{Introduction}

With the rapid development of economy, the building owner to the design of building more and more complex, is hard to imagine the specific construction of concrete form. But BIM technology is adopted to improve the visual modeling of building model, the project from the beginning to the perspective of a sand table model show in front of us, giving us the most real visual sense [1-2]. It provides information on all aspects of the construction at the same time, so in the whole process of project implementation, project from construction - construction - delivery operation in the whole life cycle can be completed in the visualization of state project communication and decision making. At home due to the use of BIM late, also did not form a unified application standards, standards are compiled, BIM model as data storage architecture information carrier, it can through a variety of digital technology for each construction project digital information model is put forward, and on this basis to assist the management of the whole life cycle of project completion.

Construction engineering design as an important part of the construction project, the design quality of the entire construction project investment, progress and quality have a significant impact. To effectively improve the overall quality of the construction project in our country, improve the level of our country architectural engineering design technology, management, must be well versed in the construction of technical information and management information.

In the light of the construction project based on BIM design management conducted a preliminary study, adopted mainly literature study, questionnaire and induction of research methods, with the knowledge management of construction design management and project management properties and suitability for the analysis of BIM in it; BIM in construction engineering design are expounded, the status quo of the application in the management of construction engineering design for the design and analysis of deficiencies, the enterprise design standards is not sound, the coordinated ability, data security ability needs to improve and design process need to optimization, design activity schedule, cost management to strengthen problems and their causes are analyzed.

\section{Our Theoretical Analysis}

BIM (Building Information Modeling) as a project of integrated Information platform, make some in traditional architectural engineering design mode is difficult to quantify or evaluation Information becomes relatively easy to quantify or evaluation, it also provides the project management of construction engineering design activity is more comprehensive, more reliable data 
basis [3-5], its structure is shown in figure 1. Also, all kinds of construction engineering design knowledge can be effective in this platform plus collection, cross and shunt. BIM can make break through the limitations of professional stylist, maximum limit within the scope of their own work to understand the needs of the other design professional and other project participants, more intuitive to learn the knowledge of others.

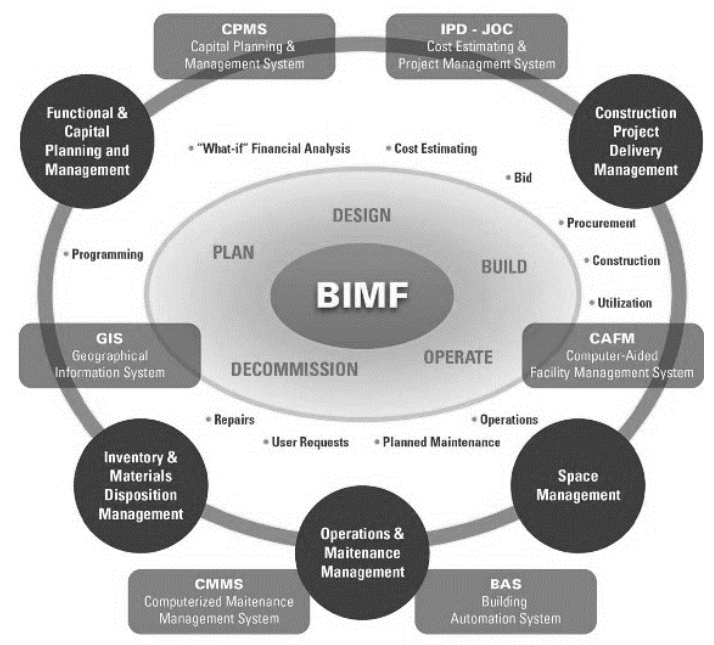

Figure 1. The structure of Building Information Modeling (BIM)

And BIM advocated collaborative design approach is more conducive to learn from the designers make the success of the project, and the design experience than in traditional architectural engineering design mode design experiences gained by the more stand the test of project construction stage or operating stage. Based on the concept of BIM in construction project design activities is not only to improve the quality of the engineering design drawings, but also the overall quality of construction engineering project. BIM has greatly enriched the construction engineering design, as it were, the means of knowledge management.

BIM is through digital technology, in the computer to establish a three-dimensional virtual building model, this model provides contains the whole life cycle of the whole building (BLM) needed information database. These information will keep the information in the integrated digital environment constantly updated and can provide access, architects, engineers, construction personnel and the owner can clear the comprehensive understanding of the project. Second, at the same time, BIM is a kind of applied in the design, construction, operation and management of whole life cycle of the whole building (BLM) digital method, this method supports the construction project integrated management environment, can make the construction project in the process of its entire significantly improve efficiency and reduce risk [6-7]. In a word, BIM emphasizes the use of digital model of project design, construction and operation of a dynamic process, the product of the BIM model is the process in the middle. And we are familiar with $2 \mathrm{~d}$ drawings, BIM model is also a kind of expression, but it integrates involves a large number of construction of whole life cycle information. So it is also a carrier, a platform. So, information and models are closely related, they constitute the core content of the BIM technology. No information BIM is a so-called geometric modelling or $3 \mathrm{~d}$ visualization; No model, BIM is architectural information graphics, architecture form or information file.

\section{BIM application in construction engineering design management}

Construction engineering design of the main content of knowledge management should be included by collecting and sorting the knowledge of the construction engineering design must be to use a variety of knowledge management technology, setting up a comprehensive knowledge platform, develop knowledge exchange and sharing environment, improve the design staff knowledge innovation ability, and to design the production accumulation of knowledge resources for standardization in the process of integration, as part of the architectural design enterprise knowledge 
used in the design of the production practice in the future [8]. Construction engineering design and management of the main goals include fundamentally improve the production quality and efficiency of architectural design companies, strengthening the construction of architectural design companies face a different market environment and project type reaction ability, improve the architectural design of enterprise's innovation ability, improve the efficiency of management of architectural design companies.

BIM as a project of integrated information platform, make some in traditional architectural engineering design mode is difficult to quantify or evaluation information becomes relatively easy to quantify or evaluation, it also provides the project management of construction engineering design activity is more comprehensive, more reliable data basis. Also, all kinds of construction engineering design knowledge can be effective in this platform plus collection, cross and shunt. BIM can make break through the limitations of professional stylist, maximum limit within the scope of their own work to understand the needs of the other design professional and other project participants, more intuitive to learn the knowledge of others. And BIM advocated collaborative design approach is more conducive to learn from the designers make the success of the project, and the design experience than in traditional architectural engineering design mode design experiences gained by the more stand the test of project construction stage or operating stage. Based on the concept of BIM in construction project design activities is not only to improve the quality of the engineering design drawings, but also the overall quality of construction engineering project. BIM has greatly enriched the construction engineering design, as it were, the means of knowledge management.

\section{Process of construction engineering design management based on BIM}

Construction project management of engineering design captures the project of construction project design activities, but in the use of project management in construction project design activities of quality, progress, cost control at the same time, the properties of the construction engineering design activities itself could not avoid, namely design activities process essentially is primarily a mental activity. Construction engineering design deliverables are intangible products (mainly for engineering drawings), and the construction of the project deliverables is tangible products, engineering is the process of material processing and production, the process of design is the processing and comprehensive knowledge. That is a qualitative difference to make project management of construction engineering design management is not enough comprehensive, shown in figure 2 is a primary stage of BIM common design process.

In the early stages of BIM application and the design process is not too big change, scheme design, preliminary design phase and construction drawing design stage division is very clear, but in order to better play to the synergy of BIM, some businesses begin to pay attention to professional coordination within each design stage. In this process is an important reason for the application of BIM is subject to the relevant hardware and software level. In simple terms, the majority of BIM software requirement for computer configuration is very high, and the so-called "top configuration" computer is difficult to carry a large project. So in this condition, the designer will first define a design principles (such as the origin coordinate control project), and then different professional modeling, some large projects and even within the same profession also need partition modeling. In complex design node or key point, use "Link (Link)" mode to integrate designs or designs exported to a dedicated software (such as Autodesk Navisworks) to work together. When a phase of the collaborative work smoothly completed, and then into the next phase of the design work. 


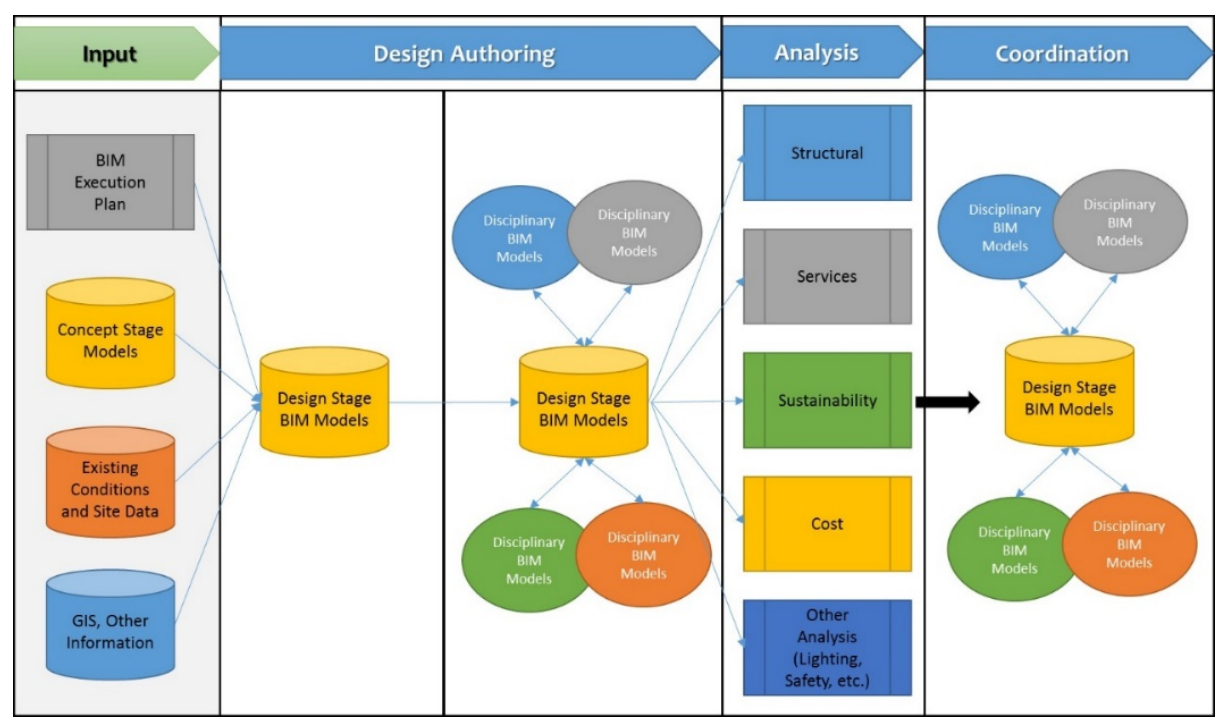

Figure 2. Process structure of construction engineering design management based on BIM

\section{Practices analysis of construction engineering design management based on BIM}

Construction engineering design process is a typical process of knowledge production, its core is the processing and comprehensive knowledge of construction engineering design, strengthening the knowledge management of construction engineering design, help to promote the quality of the design from the essence, strengthen construction project management of engineering design, help to design activities of quality, progress, cost target management and control, construction engineering design based on BIM management case is shown in figure 3.

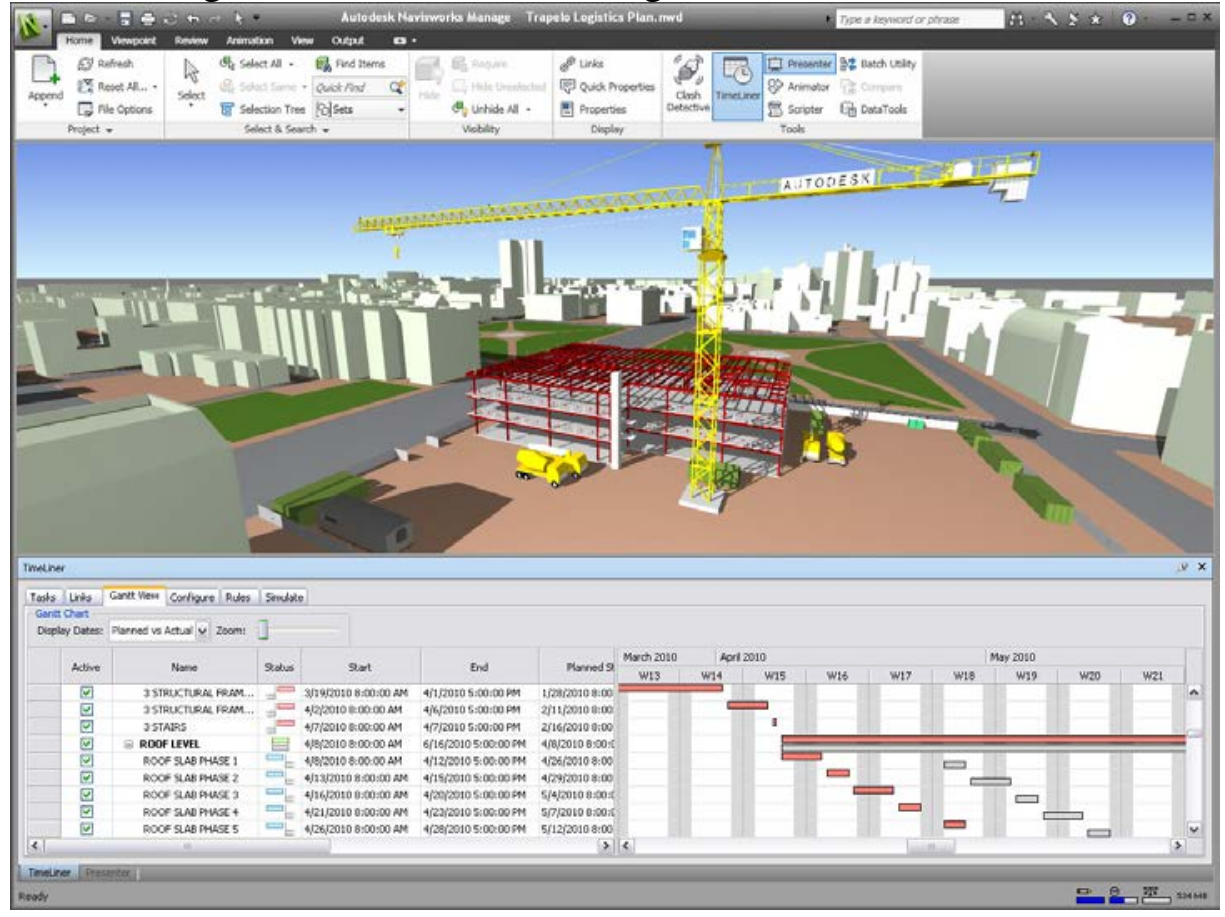

Figure 3. One case construction engineering design management based on BIM

Construction engineering design management should include two attributes knowledge management and project management. And BIM can not only satisfy the requirement of the construction project design activities in project management, but also a targeted adapted to the knowledge management of construction engineering design requirements, and make the design of construction engineering project management and knowledge management organic union. Based on BIM application in our country present stage construction engineering design present situation analysis, in this paper, the author thinks that although the development of BIM is still in its infancy, 
but has quickly become one of the main trend for the development of construction field. The construction sector, the arrival of the BIM, is both opportunity and challenge. Relevant enterprises to improve their competitiveness, must be prepared to BIM talent reserves, develop in line with the BIM project related principle and method of interest distribution, and related theory research of active lay a foundation for effective policy support.

\section{Conclusion}

At present, there has carried out some BIM project, also gained some successful experience, but in the whole building engineering design industry, the present situation of the application of BIM in the design phase is not satisfactory. The vast majority of fund, the architectural design enterprise with rich technical strength is not enough have no plans to do business of BIM, not even heard of BIM; some develop business of BIM enterprises, including the leader of the industry, still on the stage of exploration practice in BIM applications. So far, BIM is mainly used in software operating level, the thought of collaborative design needs to be promoted, and in order to better realize the collaborative design, design standards, design process needs to be optimized.

\section{Acknowledgements}

Qinghai Social Science Foundation: Study on the degree of the economy of Qinghai province from the perspective of the coordination of ecological red line (14030).

\section{References}

[1] Succar B. Building information modelling framework: A research and delivery foundation for industry stakeholders[J]. Automation in construction, 2009, 18(3): 357-375.

[2] Eastman C, Teicholz P, Sacks R, et al. BIM handbook: A guide to building information modeling for owners, managers, designers, engineers and contractors[M]. John Wiley \& Sons, 2011.

[3] Azhar S. Building information modeling (BIM): Trends, benefits, risks, and challenges for the AEC industry[J]. Leadership and Management in Engineering, 2011, 11(3): 241-252.

[4] Azhar S, Nadeem A, Mok J Y N, et al. Building information modeling (BIM): A new paradigm for visual interactive modeling and simulation for construction projects[C]//Proc., First International Conference on Construction in Developing Countries. 2008: 435-446.

[5] $\mathrm{Gu} \mathrm{N}$, London K. Understanding and facilitating BIM adoption in the AEC industry[J]. Automation in construction, 2010, 19(8): 988-999.

[6] Singh V, Gu N, Wang X. A theoretical framework of a BIM-based multi-disciplinary collaboration platform[J]. Automation in Construction, 2011, 20(2): 134-144.

[7] Dainty A R J, Cheng M I, Moore D R. Competency-based model for predicting construction project managers’ performance[J]. Journal of Management in Engineering, 2005, 21(1): 2-9.

[8] Zhang J P, Hu Z Z. BIM-and 4D-based integrated solution of analysis and management for conflicts and structural safety problems during construction: 1. Principles and methodologies[J]. Automation in construction, 2011, 20(2): 155-166. 